\title{
DOMESTIC VIOLENCE IN PREGNANCY: PREVALENCE AND CHARACTERISTICS OF THE PREGNANT WOMAN
}

Fátima Susana Jesus Almeida, Emília Carvalho Coutinho, João Carvalho Duarte, Cláudia Margarida Balula Chaves, Paula Alexandra Batista Nelas, Odete Pereira Amaral and Vitória Castro Parreira

Aims and objectives. To determine the prevalence of domestic violence (physical, psychological or sexual) during pregnancy and to characterise these women.

Background. Pregnant women are not immune to domestic violence and therefore may be subject to any form of physical, psychological or sexual violence by partners. Health professionals' knowledge and awareness are important in the identification and intervention of pregnant women who experience domestic violence.

Methods. Quantitative, descriptive, correlational study, using a nonprobabilistic convenience sample consisting of a total of 852 postpartum women, of whom 370 were experiencing domestic violence according to the criteria adopted through the modified scale of prevalence, applied between February-June 2012 in two Portuguese public health institutions. Authorisation was given by the Ethics Committees/Administration Councils of both institutions involved and the National Committee of Data Protection.

Results. The prevalence of DV during pregnancy was 43_4\% (physical violence $-21.9 \%$; psychological violence $-43.2 \%$; and sexual violence $-19.6 \%$ ). These women had the following profile: immigrant $(\mathrm{OR}=5.70 ; \mathrm{IC95} \% 3.32-9.78)$, non-Caucasian $(\mathrm{OR}=6.27$; IC95\% 3.76-10.46), single/divorced/widowed (OR = 2.28; IC95\% 1.70-3.05), academic qualifications up to year $9(\mathrm{OR}=4.94$; IC95\% 3.31-7.37); between 10-12 years of schooling $(\mathrm{OR}=2.36 ; \mathrm{IC} 95 \%$ 1.70-3.29); unemployed $(\mathrm{OR}=2.01 ; \mathrm{IC95 \%} 1.50-2.69) ;$ and with a monthly income $<1000$ euros $(O R=1.90 ;$ IC95\% 1.44-2.50). Through logistic regression, 
the following protective factors have been identified: nationality (Portuguese), race (Caucasian) and place of residence (city).

Conclusions. Almost half of the sample had experienced some form of domestic violence. This is associated with certain sociodemographic factors identified in the study. Psychological violence was the most prevalent during pregnancy.

Relevance to clinical practice: Knowledge of the prevalence and characteristics of pregnant women who experience domestic violence is of paramount importance in planning appropriate strategies for their needs during pregnancy. Results indicate the need for nurses to intervene when warning signs of domestic violence against pregnant women are detected.

Keywords: determinants, domestic violence, pregnancy, prevalence

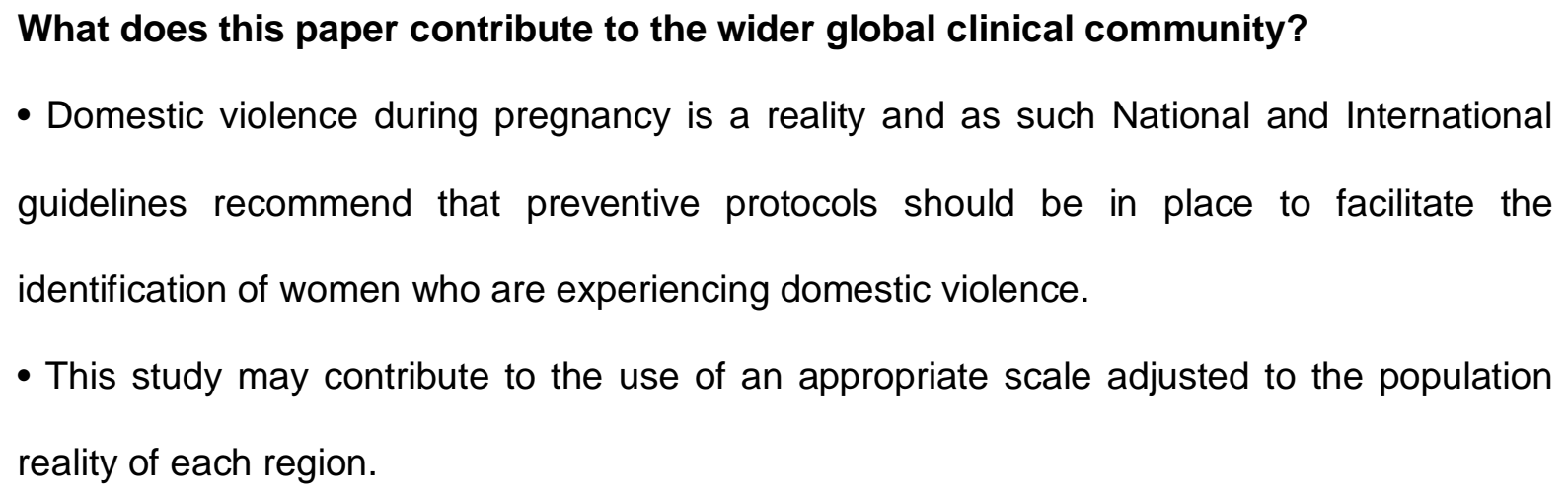

- Domestic violence during pregnancy is a reality and as such National and International guidelines recommend that preventive protocols should be in place to facilitate the identification of women who are experiencing domestic violence.

- This study may contribute to the use of an appropriate scale adjusted to the population reality of each region.

\section{INTRODUCTION}

Domestic violence (DV) is a complex and multidimensional phenomenon (Baird et al. 2016) considered as ill treatment towards human life. Nowadays, the present laws, the governmental (Portugal. Ministry of Internal Administration 2015) and nongovernmental organisations, the media and easy access to information have encouraged more people to recognise and take action against domestic violence against women; however, there is still a large number of occurrences which go unreported.

Domestic violence being considered as a public health problem and its recognition as a social and political issue have contributed to the progressive identification of its seriousness. 
The consequences of DV are damaging to the health and well-being of pregnant women as well as to the development of the child, family, community and society in general (WHO 2013).

Violence against women can be perpetrated at all stages of the life cycle, but the concern is greatest when a woman is pregnant as in these circumstances violence has a direct impact on both the mother and child. Negatively affecting their quality of life, DV can have devastating physical and psychological consequences for the pregnant woman and her child (Nasir \& Hyder 2003, Doubova et al. 2007, Audi et al. 2008, Rasmussen \& Yaktine 2009). There are several studies connecting domestic violence to pregnancy. Audi et al. (2008, p. 878) claim that 'pregnant women are not free from domestic violence. . ., a statement in agreement with Santos et al. (2010) which stated that violence against women may occur at any stage of life, and pregnancy is one of these stages.

\section{BACKGROUND}

Although pregnancy is recognised as a special period that should offer the woman pleasant conditions and a harmonious atmosphere, there are many studies connecting DV with pregnancy. Audi et al. (2008) found high prevalence of different categories of domestic violence conducted by the partner during pregnancy and revealed several factors associated with it. According to the APAV (2015b), warning signs of physical violence that can be observed in women in general who suffer from DV are as follows: asthenia, myalgias, headaches and migraines, menstrual disorders, shivering and hot flashes, digestive disorders, hypertension. Psychological warning signs are as follows: difficulty concentrating, insomnia, nightmares, memory deficiency, difficulty making decisions, sadness, distrust of others, decreased self-confidence. McGarry (2016) highlights the need for support structures so that health professionals can recognise the signs, and BradburyJones et al.(2016) defend the need for a practice framework to improve nurses' responses to intimate partner violence. Some studies point to a multifactorial condition that acts as a precursor of various types of violence, even though these factors cannot be considered as 
its direct causes (Schraiber et al. 2003). DV against women in their childbearing years can lead to serious injury and death to both mother and child. Scientific evidence suggests that women are particularly vulnerable to violence during pregnancy and the postnatal period (WHO 2005, O’Reilly 2007).

Some women, exposed to DV, feel reluctant to declare assaults by partners because they do not recognise some of the acts perpetrated against them as acts of violence (Nasir \& Hyder 2003, Kady et al. 2005, Audi et al. 2008, Medina \& Penna 2008).

At a worldwide level, DV has reached large epidemic proportions, and the prevalence of violence during pregnancy has been described by researchers as situated within a range of $1.20 \%$ (Audi et al. 2008). A study of the prevalence of DV during pregnancy perpetrated by the partner/ spouse conducted by Devries et al. (2011) in 19 countries revealed a prevalence ranging from $2 \%$ in Australia, Cambodia and Denmark to $13.5 \%$ in Uganda and more than half of the research estimated an incidence between $3.9-8.7 \%$. They also detected a higher prevalence in African and Latin American countries compared with European and Asian countries and found that during pregnancy, DV is more common than certain health conditions customary in pregnancy (Devries et al. 2011). DV during pregnancy obtained lower prevalence when compared with lifelong DV. In the same survey, DV had a higher prevalence in younger groups (between 15-35 years of age) decreasing slightly after age 35 (Devries et al. 2011).

Through the media, we frequently see the news of domestic violence perpetrated by an intimate partner in family relationships. Therefore, the focus of this study is on women during pregnancy, which sought to identify domestic violence in three areas, physical, psychological and sexual. The following questions were considered: What is the prevalence of domestic violence during pregnancy? What are the characteristics of women who have experienced domestic violence during pregnancy? Thus, the following objectives were set: to determine the prevalence of domestic violence (physical, psychological, sexual), during pregnancy and to characterize pregnant women who have experienced domestic violence. 


\section{METHODS}

\section{Design}

A quantitative, descriptive, correlational study was conducted in the postpartum services of two Portuguese public health institutions, one in the central region and another in the Greater Lisbon Area, using the modified scale of prevalence of DV conceived by Jahanfar and Malekzadegan (2007), and based on criteria used by the WHO (2005). Data were collected between February-June 2012. After a questionnaire was created for data collection, a pretest was conducted with a group of 20 women who had just given birth from another institution and there was no need to make any changes.

\section{Sample/ participants}

A total of 1285 questionnaires were distributed, and 933 questionnaires were collected; however, 81 of these were eliminated due to incompletion. Inclusion criteria were the following: being over 18, being hospitalised in the maternity ward, occurring 24 hours after childbirth: agreeing to participate in the study; understanding the questionnaire. After validation of the questionnaires, we reached a nonprobabilistic convenience sample consisting of 852 postpartum women, a participation of $66.30 \%$ of the inpatient women.

The minimum age of the mothers was 18 years old and the maximum was 44 years old with an average of $30.69 \pm 5.54$ years of age. The majority were Portuguese $(90 \%)$ and $10 \%$ were immigrants, $88.4 \%$ were Caucasian, and $11.6 \%$ were of another race. As for marital status, $68.4 \%$ were married or had common law status and $31.6 \%$ were single, divorced or widowed. Most resided in the city (64.9\%), $20.8 \%$ in small towns and $14.3 \%$ in villages. With regard to level of education, $44.8 \%$ had $10-12$ years of schooling, $33.6 \%$ higher education and finally $21.6 \% \leq 9$ years of schooling. In terms of vocational training, $45.2 \%$ had skilled occupations, $42.6 \%$ technical occupations and $12.2 \%$ unskilled professions. 


\section{Ethical considerations}

The study abided by the primary guidelines: the right to self-determination, privacy, anonymity and confidentiality, protection from discomfort and injury and lastly, receiving fair and equitable treatment. This study was conducted according to the ethics guidelines set out in the Declaration of Helsinki. The questionnaire was submitted to the National Data Protection Commission (Authorisation № 4397/2012). Authorisation was given by both Presidents of the Management and Ethics Committee Councils of the two health institutions where the study was conducted as it complied with the general principles of ethics in research (The Greater Area of Lisbon - Reference no. 5/12/CES; Central Region Reference no. 1314/70).

The women were approached by the nurse on duty who informed them of the study. Those who volunteered to participate in the study were provided with all of the necessary information and were asked to sign the consent form. The questionnaire was filled in out in a specific space set out for the effect without the presence of their partners. Anonymity was guaranteed and so was the confidentiality of the data. All were informed that their participation was free and that they may withdraw their participation at any time of the study and they would not be jeopardised or benefitted in any way for having participated. After completing the questionnaire, the respondents placed their completed questionnaire in a closed envelope which was then placed by them in a closed box, therefore maintaining confidentiality.

\section{Data collection}

The data collection instrument included sociodemographics variables, partner characteristics and variables regarding the events of the previous 12 months and their last pregnancy. To classify the women who had experienced DV, the adjusted prevalence scale of domestic violence by Jahanfar and Malekzadegan (2007), based on criteria set by the WHO (2005) in a study of DV, was used. This scale contains 
questions related to behaviour, including acts of physical, psychological and sexual violence (SV). These cut-off groups are those presented by the authors of scale (Jahanfar \& Malekzadegan 2007), which include information on financial and psychological violence (PsV). It comprises of a list of 31 items questioning women on the conduct of their companions/spouses with them for the previous 12 months and current pregnancy.

The first nine questions refer to physical violence and enquire whether the woman was (1) threatened with a firearm or weapon (knife/blade); (2) slapped; (3) punched; (4) kicked (kicks); (5) pushed; (6) hurt (injured); (7) burned; (8) beaten until resulting in bone fractures; (9) beaten until injury was done to internal organs. Physical violence (PV) is classified as mild if the answer to at least one of the first five questions is yes, moderate if more than one of the first five questions were answered yes and severe if at least one of the answers from questions 6-9 was yes. This classification was determined by the authors of the scale who also alert to the fact that any type of physical violence (classified as mild, moderate or severe) is considered to be domestic violence and even when mild it may have serious consequences including death. The intention of the authors was not to devalue any act of violence; to the contrary, they wished to highlight the acts which at times even women who suffer them do not recognise them as violent.

Questions 10-23 assess PsV and includes the following questions: (10) were you ever or are you afraid of your husband; (11) has he threatened your life; (12) threatened to hurt someone important to you; (13) abused you emotionally; (14) used offensive language with you; (15) used offensive language with your family, in their presence or not; (16) not accepted your principles and beliefs; (17) threatened your children; (18) left you or your children; (19) prevented you from leaving home; 
(20) prevented you from going out with friends, family or going to ceremonies or other places you like; (21) prevented you from getting a job; (22) prevented you from studying; (23) restricted money, food or clothing. PsV is classified as mild if less than five questions from 12-23 were answered affirmatively; moderate if five or more questions from 12-23 were answered affirmatively; and severe if question 10 and/or 11 was answered affirmatively. In this cut-off group, the authors included information on financial abuse (item 23).

Questions 24-30 assess SV and consist of the following questions: (24) were you forced to have sex; (25) did your partner/husband use violence to have sex; (26) were you physically injured due to violent sex; if so, which of the following injuries did you suffer: (27) perineal tear; (28) rectal rupture; (29) rupture of the urethra; (30) haematoma perineum. The sexual violence ranks as light if question 24 or 25 is answered affirmatively; moderate if both questions 24 and 25 are answered affirmatively; and severe if at least one of the questions from 26-30 is answered affirmatively.

\section{Data analysis}

Data analysis was performed using the SPSS version 20.0 (IBM Corp., Armonk, USA) (2012); the study of the relationship between the variables used parametric and nonparametric tests such as the chi-square test (for the study of relationships between nominal variables), Student's t-tests (to assess the differences between the averages of two groups), and binary logistic regression [for the prediction of variables through statistical odds ratio $(\mathrm{OR})]$. 
The determination of Cronbach's alpha coefficient for each of the items and for the total scale, resulting in a Cronbach's a of 0.946 , was used to evaluate the homogeneity and internal consistency of the modified scale of prevalence of DV, by Jahanfar and Malekzadegan (2007).

\section{Results}

Of the total sample, $43.4 \%$ experienced domestic violence during pregnancy including physical, psychological and sexual violence. Physical violence showed a prevalence of $21.9 \%$ (11.7\% indicated mild violence; $3.2 \%$ moderate violence and $7 \%$ serious violence). For PsV, the prevalence was $43.2 \%$ and of these, $24.9 \%$ reported mild violence; $2.9 \%$ moderate violence; and $15.4 \%$ serious violence. Sexual violence was reported by $19.6 \%$ of the women and $15.1 \%$ reported mild violence, $3.1 \%$ moderate violence and $1.4 \%$ serious violence.

The majority of new mothers (65\%) who reported experiencing DV identified their partner/spouse or ex-partner/ ex-spouse as the perpetrator of the assault.

Results according to age demonstrate that the probability of pregnant women who experience domestic violence is greater in the younger age group ( $\leq 30$ years of age) (51.4\%). Serious physical violence (9.1\%) and serious PsV (19.4\%) occur mainly in women $\leq 30$ years old, while mild physical violence (12.2\%) and mild PsV (26.4\%) occur primarily with woman over 30 years old. With regard to sexual violence, the percentages for severe violence are similar for both age groups (Table 1).

Connecting sociodemographic variables of the pregnant woman with the prevalence of domestic violence (Table 2) revealed that for almost all of the variables analysed, the differences were significant. The following differences were significant: immigrant $(O R=$ 5.70; Cl95\% 3.32-9.78); non-Caucasian (OR = 6.27; Cl95\% 3.76-10.46); single/ divorced/widowed $(\mathrm{OR}=2.28 ; \mathrm{Cl} 95 \%$ 1.70-3.05), academic qualifications up to nine years 
of schooling (OR = 4.94; CI95\% 3.31-7.37), academic qualifications 10-12 years of schooling (OR = 2.36; CI95\% 1.70-3.29), unemployed $(\mathrm{OR}=2.01 ; \mathrm{Cl} 95 \% 1.50-2.69)$ and a monthly income $<1000$ euros.

The stepwise forward LR method was used for selecting the independent variables. The selection of the independent variables is done according to the statistical significance of the score, and the removal of a variable is done according to the significance of the likelihood ratio (Marôco 2011). To determine the significance of the variables (age, nationality, race, marital status, educational level, current employment status, overcrowding index, monthly income and place of residence), the logistic regression method forward LR was used. The logistic regression revealed that the variables nationality ( $\mathrm{v} 2$ wald $=11.837 ; p=0.001$ ), race (v2 wald $=10.289 ; p=0.001)$, marital status (v2 wald $=11.780 ; p=0.001)$, academic qualifications $(<9$ years of schooling: $v 2$ wald $=36.516 ; p=0.000 ; 10-12$ years of schooling v2 wald $=12.601 ; p=0.000)$, and place of residence $(v 2$ wald $=5.420 ; p=0.020)$ are statistically significant to the probability of experiencing domestic violence. The probability of a pregnant woman experiencing domestic violence decreases for women whose nationality is Portuguese $66.7 \%$, who are Caucasian $61.7 \%$ and who live in villages $41.4 \%$. On the other hand, the risk of experiencing domestic violence increases by $76.5 \%$ for single women, by $274.1 \%$ for those with academic qualifications up to year 9 and $91.7 \%$ when academic qualification is between years 10-12. The model has a high sensitivity of $82.0 \%$ and adequate specificity (54.6\%). Therefore, and according to Table 3, marital status (single/divorced/widowed) and educational level ( $\leq 9$ years of schooling and 10-12 years of schooling) are factors associated with DV. On the other hand, nationality (Portuguese), race (Caucasian) and place of residence (city) revealed to be protective factors against DV.

Of the 852 women who constitute the sample, a total of $848(99.5 \%)$ were included in the logistic regression model; therefore, $0.5 \%$ were not included. The estimated probability of success, that is the probability of women not experiencing violence, is of 1.304 (observed ratio), with a statistically significant chi-square Wald ( $v 2 w=14,706 ; p=0.000$ ), which tells 
us that the least one of the independent variables is related to the regression model $(\operatorname{logit} p)$. The pseudo R2 of McFadden (R2MF $=0.847$ ) indicates that the model is of adequate quality. The model states that there are 176 false-positive cases, and 90 false negatives. These figures reflect a sensitivity of the model of $52.2 \%$ and a specificity of $81.3 \%$.

\section{Table 1}

\section{Table 2}

\section{Table 3}

\section{DISCUSSION OF RESULTS}

The main objectives of this study were to determine the prevalence of DV in pregnancy and to identify protective factors and determinants of pregnant women who experience domestic violence.

The percentage of pregnant women who had experienced DV in this study were $43.4 \%$. The results are similar to those found by Rasmussen and Yaktine (2009) who presented a prevalence of $41.6 \%$. However, other studies have lower numbers for women who have experienced DV. Such is the case with the studies conducted by Bacchus et al. (2006), Bonomi (2003), and Koenig et al. (2006) which report that the majority of new mothers, namely $97.5 \%$ ( 870 of 892 women), $92.4 \%$ (110 of 119 women) and $89.4 \%$ (567 of 634 women), respectively, did not experience DV as the prevalence for DV was 2.5, 7.6 and $10.6 \%$, respectively. This low prevalence may have been due to the fact that they were asked only if they had or not experienced DV. Considering these results, the decision was made to use the modified scale of prevalence (Jahanfar \& Malekzadegan 2007) as it allows for the identification of DV and all of the subtypes of violence (physical, psychological and sexual). Individual analysis of each type revealed that $21.9 \%$ reported physical violence, and of these, $11.7 \%$ reported mild violence, $3.2 \%$ moderate violence and $7 \%$ serious violence. These data corroborate those found by Oweis et al. (2010), who reported the existence of new mothers who have experienced physical violence before pregnancy. The prevalence of PsV was $43.2 \%$; $24.9 \%$ of participants reported having experienced mild violence, $2.9 \%$ 
moderate violence and $15.4 \%$ serious violence, with statistic differences related to age. Also, in their study, Doubova et al. (2007) found that $31.1 \%$ of women were exposed to psychological and/or physical and/or sexual violence by their male partner during their current pregnancy, $10 \%$ reported combined violence and $21 \%$ isolated violence. Also, they report that PsV was the most common as is the case with this study. Deveci et al. (2007) and Oweis et al. (2010) had a higher prevalence of verbal/PsV than physical violence in their findings, as was the case with our study. With regard to sexual violence, there was a prevalence of $19.6 \%$ of new mothers who reported SD, where $15.1 \%$ reported having suffered mild violence; $3.1 \%$ moderate violence and $1.4 \%$ serious violence. These data are also consistent with those found by Oweis et al. (2010), who revealed the presence of sexual violence, although in less significant frequency when compared to other types of violence. The data obtained in our research on the various forms of violence are similar to those reported by Moura et al. (2011) and Okada et al. (2015) who ascertained that the frequency of DV in pregnancy was significant, with PsV referred to as the most significant while physical violence and sexual violence were less prevalent.

The prevalence of violence associated with sociodemographic variables which characterise these pregnant women who experience DV revealed that age was not an influential factor. According to the Internal Security Annual Report (SSI 2013) and the Portuguese Association for Victim Support (APAV 2015a,b), the ages of the women who have identified themselves as having experienced DV in Portugal ranged between 25-54 years. Devries et al. (2011), in a study on DV during pregnancy, found a higher prevalence in the age group between 1535 years of age and that DV decreased slightly after age 35. However, there were no differences found which confirms the findings in this study that age may not be a factor associated with DV.

After a binary logistic regression, factors associated with DV were observed. Protective factors against DV were: nationality (Portuguese), race (Caucasian) and living in a city. On the other hand, marital status (single/divorced/widowed) and academic qualifications (<9 
years of schooling and 10-12 years of schooling) were found to be risk factors. A study conducted by Jeanjot et al. (2008) found that DV was higher among immigrant women. Furthermore, this is highlighted by Duarte and Oliveira (2012, p. 234) who state that DV against immigrant women is a more complex problem with serious consequences because in addition to being confronted with gender inequalities, they are also faced with the language and racial barriers of the host society. The results found by Jeanjot et al. (2008) showed a prevalence of DV history 35 times higher in women of other races in comparison with Caucasians. In our study, the prevalence is 6.2 times higher. Also, Boy and Salihu (2004) and Audi et al. (2008) presented women of other races, especially Black, as a risk factor for DV. The study by Coutinho et al. (2015) reveals that the immigrant nationality of the partner is also a factor very significantly associated with domestic violence during pregnancy $(\mathrm{OR}=5.29, \mathrm{Cl} 95 \% 3.38-8.29)$. With regard to the marital status variable, the risk of domestic violence is 2.28 times greater for single/divorced/widowed women in comparison with those who are married. Given the results, it may be said that these findings corroborate the results found by Yanikkerem et al. (2006), whereby DV in pregnant women occurs more significantly in women who are not married than in those who are married or in a common law relationship. Paz (2006) also has similar results in his research. Academic qualifications were also found to be a predicting variable for DV. The odds ratio $(O R=4.94$; IC95\% $3.31-$ 7.37 and $\mathrm{OR}=2.36$; IC95\% 1.70-3.29) confirmed that women with up to nine years of schooling and with academic qualification between years 10-12, respectively, were at risk of DV. The results echoed those found by Yanikkerem et al. (2006), Paz (2006), Audi et al. (2008), Hammoury et al. (2009), ascertaining that pregnant women with lower education levels more often experience DV.

With regard to current employment status, $59.5 \%$ of new mothers who were treated with violence were employed and $40.5 \%$ were unemployed, confirming that, according to the odds ratio in this study, the probability of experiencing DV was higher among unemployed women. This finding is consistent with the results obtained by Paz (2006), that unemployed 
women are more susceptible to the risk of DV; however, the adjusted logistic regression did not prove this variable as a predictor.

One of the limitations of the study is the sampling technique which was nonprobabilistic and therefore not representative of the study population. Another limitation is the fact that domestic violence is still taboo and the puerperium is considered a period of happiness for the couple which can result in possible limitations in the answers as they may not be sincere as they may reflect desired behaviour and no tactual behaviour.

\section{CONCLUSION}

Domestic violence in general and among pregnant women in specific is often still concealed and consented to by the person who suffers from it which is why studies on this area are scarce; therefore, this study contributes to the uncovering of the reality of DV in Portugal. We can conclude that the prevalence of DV in the sample was $43 \_4 \%$ and that PsV had the highest percentage. After logistic regression, regarding the sociodemographic profile of pregnant women who have experienced abuse, the risk factors identified were marital status and level of education. We identified nationality, race and place of residence as protective factors against ill treatment during pregnancy.

\section{RELEVANCE TO CLINICAL PRACTICE}

This study allowed us to identify the magnitude of the problem of DV and to profile pregnant women who experience it. This is relevant to the practice of nurses, obstetricians and any other medical provider of health care to pregnant women to form and plan strategies that are appropriate for different contexts.

In finding that nearly half of pregnant women suffer from domestic violence, it would be good professional practice to introduce a measuring instrument that facilitates the identification of 
women who are ill-treated during pregnancy. It is also important to make healthcare professionals aware of the situation and to provide them with specific training on the matter.

\section{Acknowledgment}

This study is financed by national funds through FCT - Fundação para a Ciência e Tecnologia, I.P., under the project UID/Multi/04016/2016. Furthermore, we would like to thank the Instituto Politécnico de Viseu and CI\&DETS for their support.

\section{Contributions}

Conception and study design: FS, EC, JD; data analysis: FS, EC, JD; manuscript preparation: FS, EC, JD, CC, PN, OA, VP and discussing, revising, approving the article: FS, $E C, J D, C C, P N, O A, V P$

\section{Funding}

Financial support was provided by FCT and the Centro de Estudos em Educação Tecnologia e Saúde, Portugal. Financial support was given to the study by Portuguese Foundation for Science and Technology, and Centro de Estudos em Educação Tecnologia e Saúde, Portugal.

\section{Conflict of interest}

The authors declare that they have no conflict of interests. 


\section{References}

APAV. (2015a). APAV Statistics Annual Report 2014. Lisbon: Portuguese Association for Victim Support.

APAV. (2015b). Domestic Violence Newsletter. Retrieved 2016-11-20, 2016, from http://www.apav.pt/apav_v3/index.php/pt/folhas-informativas

Audi, C. A. F., Segall-Corrêa, A. M., Santiago, S. M., Andrade, M. G. G., \& Pèrez-Escamila, R. (2008). Violence against pregnant women: prevalence and associated fators. Revista de saude publica, 42(5), 877-885.

Bacchus, L., Mezey, G., Bewley, S., \& Haworth, A. (2006). Prevalência da violência doméstica quando as parteiras questionam por rotina durante a gravidez. Revista Sociedade portuguesa de obstetrícia e ginecologia, XXIX(5), 273-277.

Baird, K., Creedy, D., \& Mitchell, T. (2016). Intimate Partner Violence and Pregnancy Intentions: A Qualitative Study. J Clin Nurs. doi: 10.1111/jocn.13394

Bonomi, M. R. (2003). Characterisation of conjugal violence during pregnancy in women with a history of domestic violence. (Bacharel em Psicologia), Federal University of São Carlos, São Paulo, Brasil.

Boy, A., \& Salihu, H. M. (2004). Intimate partner violence and birth outcomes: a systematic review. Int J Fertil Womens Med, 49(4), 159-164.

Bradbury-Jones, C., Clark, M. T., Parry, J., \& Taylor, J. (2016). Development of a practice framework for improving nurses' responses to intimate partner violence. J Clin Nurs. doi: 10.1111/jocn.13276

Coutinho, E., Almeida, F., Duarte, J., Chaves, C., Nelas, P., \& Amaral, O. (2015). Factors Related to Domestic Violence in Pregnant Women. Procedia - Social and Behavioral Sciences, 171(0), 1280-1287. doi: http://dx.doi.org/10.1016/j.sbspro.2015.01.242

Deveci, S. E., Acik, Y., Gulbayrak, C., Tokdemir, M., \& Ayar, A. (2007). Prevalence of domestic violence during pregnancy in Turkish community. Southeast Asian Journal of Tropical Medicine and Public Health, 38(4), 754-760.

Devries, K. M., Kishorb, S., Johnsonc, H., Stockld, H., Bacchuse, L. J., Garcia-Morenof, C., \& Wattsg, C. (2011). Violence by intimate partner during pregnancy: data analysis of prevelance in 19 countries. Reproductive Health Matters Journal, 5(1), 110-124.

Doubova, S. V., Pámanes-González, V., Billings, D. L., \& Torres-Arreola, L. P. (2007). Violent partners among pregnant women in Mexico City. Revista Saúde Pública, 41(4), 582-590.

Duarte, M., \& Oliveira, A. (2012). Women on the edge: domestic violence and immigrant women. Sociology, Faculty of Letters Journal of Porto University, XXIII, 223-237.

Hammoury, N., Khawaja, M., Mahfoud, Z., Afifi, R. A., \& Madi, H. (2009). Domestic Violence against Women during Pregnancy: The Case of Palestinian Refugees Attending an Antenatal Clinic in Lebanon. Journal of Women's Health (15409996), 18(3), 337-345. doi: 10.1089/jwh.2007.0740

Jahanfar, S., \& Malekzadegan, Z. (2007). The Prevalence of Domestic Violence Among Pregnant Women Who Were Attended in Iran University of Medical Science Hospitals. Journal of Family Violence, 22(8), 643-648. doi: 10.1007/s10896-007-9084-0

Jeanjot, I., Barlow, P., \& Rozenberg, S. (2008). Domestic Violence During Pregnancy: Survey of Patients and Healthcare Providers. Journal of Women's Health (15409996), 17(4), 557-567. doi: 10.1089/jwh.2007.0639

Kady, D. E., Gilbert, W. M., Xing, G., \& Smith, L. H. (2005). Maternal and neonatal outcomes of assaults during pregnancy. Obstetrics \& Gynecology, 105(2), 357-363.

Koenig, L. J., Whitaker, D. J., Royce, R. A., Wilson, T. E., Ethier, K., \& Fernandez, M. I. (2006). Physical and Sexual Violence During Pregnancy and After Delivery: A Prospective Multistate Study of Women With or at Risk for HIV Infection. Am J Public Health, 96(6), 1052-1059. doi: 10.2105/AJPH.2005.067744

Marôco, J. (2011). Statistical analysis with SPSS Statistics. $5^{\mathrm{a}}$ ed. Pero Pinheiro: Report Number

McGarry, J. (2016). Domestic violence and abuse: an exploration and evaluation of a domestic abuse nurse specialist role in acute health care services. J Clin Nurs. doi: $10.1111 /$ jocn. 13203

Medina, A. B. C., \& Penna, L. H. G. (2008). Violence during gestation: literature review 2000 to 2005. . Esc Anna Nery Nursing Journal, 12(4), 793-798.

Moura, L. M. A., Pereira, L. C., \& Morais, S. C. R. V. (2011). The prevalence of domestic violence among women cycle. From 
http://www.ufpi.br/19sic/Documentos/RESUMOS/Vida/Luciane\%20Maria\%20Alves\%20de\%20Moura. pdf

Nasir, K., \& Hyder, A. A. (2003). Violence against pregnant women in developing countries: review of evidence. European Journal of Public Health, 13(2), 105-107.

Okada, M. M., Hoga, L. A. K., Borges, A. L. V., Albuquerque, R. S. d., \& Belli, M. A. (2015). Domestic violence in pregnancy. Nursing Proceedings from São Paulo, 28, 270-274.

O'Reilly, R. (2007). Domestic violence against women in their childbearing years; A review of the literature. Contemporary Nurse: A Journal for the Australian Nursing Profession, 25(1/2), 1321.

Oweis, A., Gharaibeh, M., \& Alhourani, R. (2010). Prevalence of Violence During Pregnancy: Findings from a Jordanian Survey. Maternal \& Child Health Journal, 14(3), 437-445. doi: 10.1007/s10995-009-0465-2

Paz, A. (2006). Violence by intimate partner against pregnant women in the family health programme. Recife: Federal Unitversity of Pernambuco.

Portugal. Ministery of Internal Adminsitration. (2015). Comesntic Violence - 2014. Annual Monitorization Report. Lisbon.

Rasmussen, K. M., \& Yaktine, A. L. (2009). Weight Gain During Pregnancy: Reexamining the Guidelines. Washington (DC): The National Academies Press.

Santos, S. A., Lovisi, G. M., Valente, C. C. B., Legay, L., \& Abelha, L. (2010). Domestic violence during gestation: a descriptive study in a basic health unit in Rio de Janeiro. Cadernos de Saúde Colectiva, 18(4), 483-493.

Schraiber, L., Oliveira, A. F., Hanada, H., Figueiredo, W., Couto, M., Kiss, L., \& Pinho, A. (2003). Violence experienced: pain without a name. Interface-Comunication, Health, Education, 7, 41-54.

SSI. (2013). Annual Report of Internal Security. Lisbon: Internal Security System. GeneralSecretary Office.

WHO (2005). WHO Multi-country Study on Women's Health and Domestic Violence against Women. Initial results on prevalence, health outcomes and women's responses. Geneva. World Health Organization.From file://C:/Users/p41/Desktop/1\%20violencia\%20JCN/violencia\%20artigos\%20de\%20apoio/W HO\%202005_summary_report_English2.pdf

WHO. (2013). Global and regional estimates of violence against women: prevalence and health effects of intimate partner violence and non-partner sexual violence. Geneva: World Health Organization.

Yanikkerem, E., Karadas, G., Adiguzel, B., \& Sevil, U. (2006). Domestic violence during pregnancy in Turkey and responsibility of prenatal healthcare providers. Am J Perinatol, 23(2), 93-103. doi: 10.1055/s-2006-931802 

Table 1 - Prevalence of DV according to age

\begin{tabular}{|c|c|c|c|c|c|c|c|c|}
\hline \multirow{2}{*}{$\begin{array}{l}\text { Age } \\
\text { Prevalence of DV }\end{array}$} & \multicolumn{2}{|c|}{$\begin{array}{c}\leq 30 \text { years } \\
\text { (1) }\end{array}$} & \multicolumn{2}{|c|}{$\begin{array}{c}\geq 31 \text { years } \\
(2)\end{array}$} & \multicolumn{2}{|c|}{ Total } & \multirow[t]{2}{*}{$\mathrm{X}^{2}$} & \multirow[t]{2}{*}{$\mathbf{P}$} \\
\hline & $\mathbf{n}$ & $\%$ & $\mathbf{n}$ & $\%$ & $\mathbf{n}$ & $\%$ & & \\
\hline \multicolumn{9}{|c|}{ Classification of Physical Violence } \\
\hline Mild Violence & 46 & 11,3 & 54 & 12,2 & 100 & 11,7 & & \\
\hline Moderate Violence & 15 & 3,7 & 12 & 2,7 & 27 & 3,2 & 5,774 & 0,123 \\
\hline Serious Violence & 37 & 9,1 & 23 & 5,2 & 60 & 7,0 & & \\
\hline No violence & 310 & 76,0 & 355 & 80,0 & 665 & 78,1 & & \\
\hline \multicolumn{9}{|c|}{ Classification of Psychological Violence } \\
\hline Mild Violence & 95 & 23,3 & 117 & 26,4 & 212 & 24,9 & & \\
\hline Moderate Violence & 15 & 3,7 & 10 & 2,3 & 25 & 2,9 & 11,835 & 0,008 \\
\hline Serious Violence & 79 & 19,4 & 52 & 11,7 & 131 & 15,4 & & \\
\hline No violence & 218 & 53,6 & 265 & 59,7 & 483 & 56,8 & & \\
\hline \multicolumn{9}{|c|}{ Classification of Sexual Violence } \\
\hline Mild Violence & 76 & 18,6 & 53 & 11,9 & 129 & 15,1 & & \\
\hline Moderate Violence & 16 & 3,9 & 10 & 2,3 & 26 & 3,1 & 10,110 & 0,018 \\
\hline Serious Violence & 5 & 1,2 & 7 & 1,6 & 12 & 1,4 & & \\
\hline No violence & 311 & 76,2 & 374 & 84,2 & 685 & 80,4 & & \\
\hline \multicolumn{9}{|c|}{ Classification of Total Violence } \\
\hline With Violence & 190 & 46,6 & 180 & 40,5 & 370 & 43,4 & & \\
\hline No violence & 218 & 53,4 & 264 & 59,5 & 482 & 56,6 & 3,145 & 0,044 \\
\hline
\end{tabular}


Table 2 - Prevalence of DV versus Socio-demographic Variables

\begin{tabular}{|c|c|c|c|c|c|c|c|c|c|}
\hline \multirow{2}{*}{$\begin{array}{l}\text { Prevalence of DV } \\
\text { Variables }\end{array}$} & \multicolumn{2}{|c|}{$\begin{array}{c}\text { With } \\
\text { Violence } \\
(1) \\
\end{array}$} & \multicolumn{2}{|c|}{$\begin{array}{c}\text { No } \\
\text { Violence } \\
(2) \\
\end{array}$} & \multicolumn{2}{|c|}{ Total } & \multirow[t]{2}{*}{ OR } & \multicolumn{2}{|c|}{$\mathrm{Cl} 95 \%$} \\
\hline & $n$ & $\%$ & $n$ & $\%$ & $n$ & $\%$ & & Min. & Max. \\
\hline \multicolumn{10}{|l|}{ Age } \\
\hline$\leq 30$ years & 190 & 51,4 & 218 & 45,2 & 408 & 47,9 & \multirow{2}{*}{1,28} & \multirow{2}{*}{0,97} & \multirow{2}{*}{1,68} \\
\hline$\geq 31$ years $^{*}$ & 180 & 48,6 & 264 & 54,8 & 444 & 52,1 & & & \\
\hline \multicolumn{10}{|l|}{ Nationality } \\
\hline Immigrant & 67 & 18,1 & 18 & 3,7 & 85 & 10,0 & \multirow{2}{*}{5,7} & \multirow{2}{*}{3,32} & \multirow{2}{*}{9,78} \\
\hline Portuguese* & 303 & 81,9 & 464 & 96,3 & 767 & 90,0 & & & \\
\hline \multicolumn{10}{|l|}{ Race } \\
\hline Non-Caucasian & 79 & 21,4 & 20 & 4,1 & 99 & 11,6 & \multirow[b]{2}{*}{6,27} & \multirow[b]{2}{*}{3,76} & \multirow[b]{2}{*}{10,46} \\
\hline Caucasian* & 291 & 78,6 & 462 & 95,9 & 753 & 88,4 & & & \\
\hline \multicolumn{10}{|l|}{ Marital status } \\
\hline $\begin{array}{l}\text { Single/ Divorced/ } \\
\text { Widowed }\end{array}$ & 154 & 41,6 & 115 & 23,9 & 269 & 31,6 & \multirow[b]{2}{*}{2,28} & \multirow[b]{2}{*}{1,70} & \multirow[b]{2}{*}{3,05} \\
\hline $\begin{array}{l}\text { Married/Common } \\
\text { Law* }^{*}\end{array}$ & 216 & 58,4 & 367 & 76,1 & 583 & 68,4 & & & \\
\hline \multicolumn{10}{|l|}{$\begin{array}{l}\text { Academic } \\
\text { Qualifications }\end{array}$} \\
\hline $\begin{array}{l}\leq 9 \text { years of } \\
\text { schooling }\end{array}$ & 118 & 31,9 & 66 & 3,7 & 184 & 21,6 & 4,94 & 3,31 & 7,37 \\
\hline $\begin{array}{l}10-12 \text { years of } \\
\text { schooling }\end{array}$ & 176 & 47,6 & 206 & 42,7 & 382 & 44,8 & \multirow[t]{2}{*}{2,36} & \multirow[t]{2}{*}{1,70} & \multirow[t]{2}{*}{3,29} \\
\hline Higher education* & 76 & 20,5 & 210 & 43,6 & 286 & 33,6 & & & \\
\hline \multicolumn{10}{|l|}{$\begin{array}{l}\text { Current } \\
\text { Professional Status }\end{array}$} \\
\hline Unemployed & 150 & 40,5 & 122 & 25,3 & 272 & 31,9 & \multirow{2}{*}{2,01} & \multirow{2}{*}{1,50} & \multirow{2}{*}{2,69} \\
\hline Employed $^{*}$ & 220 & 59,5 & 360 & 74,7 & 580 & 68,1 & & & \\
\hline
\end{tabular}




\begin{tabular}{lccccccccc}
$>1$ & 280 & 75,7 & 405 & 84,0 & 685 & 80,4 & 0,59 & 0,042 & 0,83 \\
$\leq 1$ & 90 & 24,3 & 77 & 16,0 & 167 & 19,6 & & & \\
\hline $\begin{array}{l}\text { Monthly income } \\
\quad 1000 €\end{array}$ & 203 & 54,9 & 188 & 39,0 & 391 & 45,9 & & & \\
$\quad 1000 €^{* *}$ & 167 & 45,1 & 294 & 61,0 & 461 & 54,1 & 1,90 & 1,44 & 2,50 \\
\hline $\begin{array}{l}\text { Place of residence } \\
\text { Village }\end{array}$ & 63 & 17,0 & 114 & 23,7 & 177 & 20,8 & 0,59 & 0,41 & 0,83 \\
City & 39 & 10,5 & 83 & 17,2 & 122 & 14,3 & 0,20 & 0,13 & 0,31 \\
Town* & 268 & 72,4 & 285 & 59,1 & 553 & 64,9 & & & \\
\hline${ }^{*}$ Reference group & & & & & & & & &
\end{tabular}

Table 3 - Logit coefficients of the logistic regression model of the variable domestic violence in pregnancy with the predictor variables

\begin{tabular}{|c|c|c|c|c|c|c|c|c|c|}
\hline \multirow{2}{*}{$\begin{array}{l}\text { Variables } \\
\text { Nationality (Portuguese) }\end{array}$} & \multirow{2}{*}{$\begin{array}{c}\mathbf{b} \\
-1.099\end{array}$} & \multirow{2}{*}{$\begin{array}{c}\text { s.e. } \\
0.319\end{array}$} & \multirow{2}{*}{$\begin{array}{l}\mathbf{X}_{\text {Wald }}^{2} \\
11.837\end{array}$} & \multirow{2}{*}{$\begin{array}{c}\text { gl } \\
1\end{array}$} & \multirow{2}{*}{$\begin{array}{c}\mathbf{p} \\
0.001\end{array}$} & \multirow{2}{*}{$\begin{array}{c}\operatorname{Exp}(\mathbf{B}) \\
\text { OR } \\
0.333 \\
\end{array}$} & \multirow{2}{*}{$\begin{array}{c}\text { \%Exp(B) } \\
-66.7\end{array}$} & \multicolumn{2}{|c|}{$\begin{array}{l}\text { Cl 95\% } \\
\text { Exp (B) }\end{array}$} \\
\hline & & & & & & & & 0.178 & 0.623 \\
\hline Race (Caucasian) & -0.959 & 0.299 & 10.289 & 1 & 0.001 & 0.383 & -61.7 & 0.213 & 0.689 \\
\hline Marital status (Single/ Divorced/ Widowed) & 0.568 & 0.165 & 11.780 & 1 & 0.001 & 1.765 & 76.5 & 1.276 & 2.441 \\
\hline Academic Qualifications ( $<9$ years schooling) & 1.319 & 0.218 & 36.516 & 1 & 0.000 & 3.741 & 274.1 & 2.438 & 5.738 \\
\hline Academic Qualifications (10-12 years schooling) & 0.651 & 0.183 & 12.601 & 1 & 0.000 & 1.917 & 91.7 & 1.338 & 2.745 \\
\hline Place of residence - city & -0.539 & 0.231 & 5.420 & 1 & 0.020 & 0.583 & -41.7 & 0.371 & 0.918 \\
\hline
\end{tabular}

